\title{
Exhaust emissions of a diesel engine using ethanol-in-palm oil/diesel microemulsion-based biofuels
}

\author{
Ampira Charoensaeng ${ }^{1}$, Sutha Khaodhiar ${ }^{2,3}$, David A. Sabatini ${ }^{4}$, Noulkamol Arpornpong ${ }^{5^{+}}$ \\ ${ }^{1}$ The Petroleum and Petrochemical College, Chulalongkorn University, Bangkok 10330, Thailand \\ ${ }^{2}$ Department of Environmental Engineering, Chulalongkorn University, Bangkok 10330, Thailand \\ ${ }^{3}$ The Center of Excellence on Hazardous Substance Management, Chulalongkorn University, Bangkok 10330, Thailand \\ ${ }^{4}$ School of Civil Engineering and Environmental Science, The University of Oklahoma, Oklahoma 73019, USA \\ ${ }^{5}$ Faculty of Agriculture, Natural Resources and Environment, Naresuan University, Phitsanulok 65000, Thailand
}

\begin{abstract}
The use of palm oil and diesel blended with ethanol, known as a microemulsion biofuel, is gaining attention as an attractive renewable fuel for engines that may serve as a replacement for fossil-based fuels. The microemulsion biofuels can be formulated from the mixture of palm oil and diesel as the oil phase; ethanol as the polar phase; methyl oleate as the surfactant; alkanols as the cosurfactants. This study investigates the influence of the three cosurfactants on fuel consumption and exhaust gas emissions in a direct-injection (DI) diesel engine. The microemulsion biofuels along with neat diesel fuel, palm oil-diesel blends, and biodiesel-diesel blends were tested in a DI diesel engine at two engine loads without engine modification. The formulated microemulsion biofuels increased fuel consumption and gradually reduced the nitrogen oxides $\left(\mathrm{NO}_{\mathrm{x}}\right)$ emissions and exhaust gas temperature; however, there was no significant difference in their carbon monoxide (CO) emissions when compared to those of diesel. Varying the carbon chain length of the cosurfactant demonstrated that the octanol-microemulsion fuel emitted lower $\mathrm{CO}$ and $\mathrm{NO}_{x}$ emissions than the butanol- and decanol-microemulsion fuels. Thus, the microemulsion biofuels demonstrated competitive advantages as potential fuels for diesel engines because they reduced exhaust emissions.
\end{abstract}

Keywords: Cosurfactant, Engine test, Exhaust emissions, Microemulsion biofuel, Palm oil

\section{Introduction}

Diesel engines are highly efficient and reliable power sources that have been commonly used in the manufacturing, transport, and agricultural sectors. However, the diesel fuel emissions contain harmful pollutants such as nitrogen oxides $\left(\mathrm{NO}_{\mathrm{x}}\right)$, carbon monoxide (CO), unburned hydrocarbon (UHC), particulate matter (PM), as well as greenhouse gases (e.g., $\mathrm{CO}_{2}, \mathrm{CH}_{4}, \mathrm{~N}_{2} \mathrm{O}$ ) [1-3]. These pollutants can have tremendous wide-ranging impacts on, for instance, acidification, ozone depletion, and the presence of human and ecological toxins (especially those adding to respiratory and cardiovascular problems) [4-6]. An increased awareness of and concern for environmental and health impacts is directly and indirectly enforced in many countries through exhaust emissions and pollution control initiatives. In addition, the consumption of diesel fuels is also increasing the rapid deple- tion of worldwide petroleum reserves, which are predicted to come to an end in the not too distant future. These reasons accelerate the push to conduct research in the area of vegetable oil-based fuel alternatives.

Several vegetable oils (e.g., palm oil, canola oil, soybean oil), which are renewable resources derived from agricultural feedstock, have been successfully utilized as alternatives for diesel fuels $[7,8]$ due to their similar physicochemical properties and comparable fuel performance to diesel fuels [9, 10]. The use of vegetable oils offers a potential reduction in harmful pollution generated from exhaust gas emissions. It is widely known that the high viscosity and common phase changes or freezing of vegetable oils at cold temperatures can lead to several complications in engines such as poor combustion, injector cocking, and the sticking of piston rings $[11,12]$. For this reason, it is necessary to reduce the viscosity of vegetable oils in order to improve 
engine performance. Several approaches for decreasing a vegetable oil's viscosity have been developed; they include fast pyrolysis and direct blending with diesel, transesterification, and emulsification [9, 13-15]. Transesterification is a process in which triglycerides are converted into a mixture of methyl esters (known as biodiesel) and glycerol as a byproduct through a thermo-chemical process using an alcohol, heat, and a catalyst [16, 17]. Biodiesel has higher oxygen content than diesel, which enhances its combustion efficiency, and reduces CO, UHC, and PM but produces greater $\mathrm{NO}_{\mathrm{x}}$ emissions (approximately $10 \%$ more $\mathrm{NO}_{x}$ than diesel) $[17,18]$. Moreover, many researchers tried to improve the fuel performance and emission characteristics of various types of biodiesel by adding 10-20\% alkanols (ethanol [19], butanol [20], pentanol [21]) as an oxygenate additive.

Microemulsification is another promising biofuel modification technology; it is used to create microemulsion biofuels to reduce viscosity and $\mathrm{NO}_{\mathrm{x}}$ emissions while achieving a combustion efficiency similar to that of a petroleum-based fuel [22, 23]. Microemulsion fuels are isotropic, transparent, and thermodynamically stable solutions of colloid dispersion. The microemulsion fuels are classified into Winsor Type II or water in oil (w/o) microemulsions. They are formulated by a mixture of two immiscible liquid fuels with different polarities (i.e., oils/water, oils/ethanol) using an appropriate surfactant and with or without a cosurfactant or amphiphilic molecules to stabilize all of the components. Recently, microemulsion fuels have been formed by renewable liquid fuels such as high viscosity of vegetable oil and diesel blends [22-24] mixed with supplementary viscosity reducers, ethanol and/or butanol. Due to the disadvantages of transesterification, the microemulsification of vegetable oils offer an alternative method for avoiding by-products and wastes (i.e., glycerol and wastewater) [6].

Having an appropriate surfactant system is the key parameter influencing microemulsion biofuel formation, for which a certain surfactant concentration is generally required to maintain the phase stability without any phase separation and precipitation $[3,25]$. In addition, cosurfactants (i.e., alkanols) which have a strong binding affinity to the surfactant molecules, have been used to facilitate the existing surfactant by promoting larger curvatures and higher either nonpolar oil or polar ethanol solubilization. Understanding the effect of the alkanol chain length of the cosurfactant on the formation of w/o microemulsion systems has been investigated by different researchers and our research group [26]. The results indicated that there is a correlation between the required amounts of surfactant concentrations and the chain lengths of alkanols (i.e., $n$-butanol, $n$-octanol, $n$-decanol). However, few research studies have observed the effect of alkanol as a cosurfactant in exhaust gas emissions, and there has been no publication on palm oil based microemulsion biofuels.

Environmental concerns surrounding fuels have been increasing, not only with regards to diesel but also sustainable alternative fuels. Attaphong et al. [26] formulated vegetable oil based microemulsion fuels comprising of canola oil-diesel blended with ethanol as a viscosity reducer, using anionic carboxylate-based extended surfactants and cosurfactants to stabilize and form homogenous fuels. Nguyen et al. [3] formulated canola oil-diesel micro- emulsion fuels using oleylamine and 1-octanol as a surfactant and a cosurfactant, and they also evaluated some of the fuel properties and diesel engine performance through a comparison of the microemulsion fuels and diesel fuel. Their results indicated that the microemulsion fuels had fuel properties, including the cloud point and pour point, as well as kinematic viscosity, that met the ASTM standards for biodiesel. Moreover, their results from the direct-injection (DI) diesel engine test demonstrated differences in fuel consumption: the engine using the microemulsion fuels consumed slightly more fuel than when it was run with diesel. Notably, some of the tests run with different microemulsion fuel formulations emitted lower amounts of $\mathrm{NO}_{\mathrm{x}}$ and CO emissions, compared with the amounts emitted by the conventional diesel fuel. These remarkable results thus promote the further investigation of these microemulsion fuels for use in diesel engines.

Singh et al. [27] formulated hybrid fuels consisting of coconut oil-ethanol-surfactant (butan-1-ol), and tested as a fuel in a direct injection diesel engine. The results indicated that the engine efficiency of the hybrid fuels was similar compared to a regular diesel and their efficiency was improved as the viscosity of the fuel decreased. The $\mathrm{NO}_{\mathrm{x}}, \mathrm{SO}_{2}$ and $\mathrm{CO}_{2}$ emissions of the hybrid fuels were lower compared to a diesel, but an increase in the CO emission was observed. Qi et al. [19] investigated the performance, combustion and emission characteristics of a turbocharged common rail direct injection (CRDI) diesel engine using the Tung oil-diesel-ethanol microemulsion fuels. The results indicated that the microemulsion fuels showed higher the brake specific fuel consumption (BSFC), lower smoke emissions at high engine loads. However, the $\mathrm{CO}$ and $\mathrm{HC}$ emissions at low engine loads were higher as compared to a diesel fuel.

This study aims to evaluate the fuel performance of microemulsion fuels containing palm oil (which is widely produced in Thailand) and diesel blended with ethanol, as the viscosity reducer, and stabilized by methyl oleate, as the surfactant. The effects of the cosurfactant's chain length (1-butanol, 1-octanol, and 1-decanol) on fuel consumption as well as exhaust gas emissions from the engine testing experiment were investigated. To evaluate the exhaust gas characteristics of the microemulsion fuels, this study measured the $\mathrm{CO}, \mathrm{CO}_{2}, \mathrm{NO}_{\mathrm{x}}$ emissions and exhaust gas temperatures, which offer the primary challenges for producing effective microemulsion fuels that can compare in performance to commercial-grade diesel fuel. A small-sized DI engine was used to perform the engine test, at an engine speed of 1,200 rpm and two different engine loads.

\section{Materials and Methods}

\subsection{Materials}

Food-grade palm oil (Morakot Industries PCL, Bangkok, Thailand) and commercial-grade diesel (PTT Public Company Limited, Bangkok, Thailand) were used as the oil phase in the biofuel blends. They were purchased from local suppliers in Thailand. Ethyl alcohol (99.8\% purity, anhydrous) was used as the polar phase and purchased from Acros Organics (Italmar, 
Thailand). Methyl oleate (MO, 70\% purity), selected as the surfactant, was purchased from Sigma Aldrich (Thailand). The three cosurfactants selected in this study were $n$-butanol, $n$-octanol, and $n$-decanol with $99 \%$ purity, and they were also purchased from Sigma Aldrich (Thailand).

\subsection{Methods}

\subsubsection{Palm oil-diesel microemulsion fuels}

The palm oil-diesel microemulsion fuels were prepared by mixing the diesel fuel and palm oil at the volumetric ratio of 1:1 with anhydrous ethanol, methyl oleate and the cosurfactant (1-butanol or 1-octanol or 1-decanol) at various ratios. The surfactant systems, methyl oleate and the cosurfactant mixture were prepared at a fixed mole ratio of 1:8 (i.e., $0.125 \mathrm{M}$. of methyl oleate and $1 \mathrm{M}$. of the cosurfactant). In addition, three cosurfactants with different carbon chain lengths, namely, 1-butanol, 1-octanol and 1-decanol, were used as the cosurfactant. The fixed volumetric composition of ethanol at 20 percent by volume was set based on the viscosity of the microemulsion fuels and fuel properties. While the volumes of the methyl oleate and ethanol concentrations were kept constant, the cosurfactant and palm-diesel blend ratios were varied. For these selected formulations, the phase of the microemulsion fuels was clear without any phase separation or precipitation occurring. The mixture was hand-shaken gently to obtain a homogeneous solution. The details of the microemulsion fuel preparation can be seen elsewhere [22]. Moreover, the diesel fuel, palm oil-diesel blends (PD, with a volumetric ratio of 1:1), and biodiesel-diesel blends (BD, with a volumetric ratio of 1:1) were prepared for comparison purposes.

\subsubsection{Exhaust emissions}

Fig. 1 shows a schematic diagram of the components of the diesel engine test. The engine used was a Mitsuki 418 cc (Model MIT-186FE); it had a direct injection type diesel engine (single-cylinder, air-cooled, four-stroke) with an 18:1 compression ratio. A hydraulic dynamometer (Sun ST-3 series, AC asynchronous generator) was coupled with the engine to apply power using a belt and pulley. The test engine was used without any modification. The technical specifications of the test engine are shown in Table S1. This type of engine is commonly used for light-duty agricultural and industrial applications. In addition, this engine was used as an initial (entry level) engine to test the microemulsion fuels; a future study will extend the use of these fuels to a larger engine and load. The engine test was performed at an engine speed of 1,200 $\pm 12 \mathrm{rpm}$ and two different loads ( 0.5 and $1.0 \mathrm{~kW}$ ) for the formulated microemulsion biofuels and the other fuels for comparison purposes. A digital multimeter and tachometer were used to measure the loads on dynamometer and speeds, respectively.

The fuel consumption of various biofuel formulations was determined using a $500 \mathrm{~mL}$ cylinder and digital stopwatch. Then, the consumed fuel volume and fuel density were used to calculate the fuel consumption $(\mathrm{g} / \mathrm{h})$. An exhaust emission analyzer (Testo $350 \mathrm{XL}$ ), located at the exhaust line, was used to measure the emissions and gas temperature from the engine. The specifications of the gas analyzer are reported in Table S2. The $\mathrm{NO}_{\mathrm{x}}$,

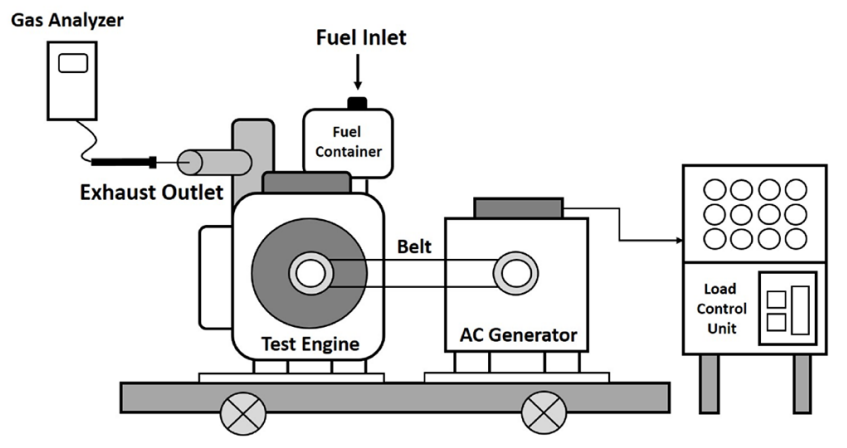

Fig. 1. Schematic chart of the experimental setup.

$\mathrm{CO}_{2}$, and $\mathrm{CO}$ emissions in the exhaust gas of the microemulsion fuels were determined. The emission index of species $i$, which is the mass of the pollutant released per unit mass of fuel burnt (g/kg fuel), was calculated using Eq. (1) [25].

$$
E I_{i}=\frac{X_{i}}{\left(X_{C O_{2}}+X_{C O}\right)}+\left(\frac{N \times M W_{i}}{M W_{f}}\right)
$$

where $X_{i}$ is the mole fraction of the species $i, X_{\mathrm{CO}_{2}}$ and $X_{\mathrm{CO}}$ are the mole fractions of $\mathrm{CO}_{2}$ and $\mathrm{CO}$ in the exhaust, $\mathrm{N}$ is the number of moles of carbon in a mole of fuel, and $M W_{i}$ and $M W_{f}$ are the molecular weights of species $i$ and the fuel, respectively. In addition, a statistical analysis for the emissions was performed with Stata version 11 (Stata-corp, TX), and the results were considered statistically significant, using a two-sided test and significance level of $0.05(p<0.05)$.

In this study, neat diesel fuel was initially injected into the test engine in order to generate the reference line. The prepared palm oil-diesel microemulsion fuels were then sequentially tested under similar circumstances to evaluate the exhaust gas emissions. The volumetric mass of the test fuel was measured and recorded before and after in each batch. Before each set of fuel tests, the new fuel sample was flushed through the engine for five minutes [3] in order to warm up the engine and rinse the remaining fuel in the engine line. Then, the engine was allowed to run for $30 \mathrm{~min}$ simultaneously after the five-minute pre-running period to evaluate the microemulsion fuel's performance. The engine load, speed, and fuel consumption were measured in order to evaluate fuel performance. BSFC, a significant parameter of engine performance, was then calculated for the tested fuels.

\section{Results and Discussion}

\subsection{Properties of the Microemulsion Fuel}

The fuel properties, water content and heat of combustion of the microemulsion biofuels were measured according to ASTM standards D6304 and D240, respectively. Table 1 summarizes the formations and fuel characteristics of the biofuels. The results showed that the kinematic viscosity of the PD fuel dramatically dropped to three times lower than that of the neat palm oil 
Table 1. Composition (\% vol.) for Palm Oil-diesel Blends, Biodiesel-diesel Blends, and Microemulsion Fuels Where the Ratio of Cosurfactant and Palm Oil-diesel Blends Was Varied. Methyl Oleate to Ethanol Ratio Was Fixed at 1:1.25

\begin{tabular}{|c|c|c|c|c|c|c|c|c|c|c|c|}
\hline \multirow[b]{2}{*}{ Sample } & \multicolumn{6}{|c|}{ Formulation } & \multicolumn{5}{|c|}{ Fuel properties } \\
\hline & Diesel & Palm oil & Surfactant & Cosurfactant & Ethanol & B100 & $\begin{array}{c}\text { Viscosity } \\
@ 40^{\circ} \mathrm{C} \\
\text { (cSt) }\end{array}$ & $\begin{array}{c}\text { Density } \\
@ 25^{\circ} \mathrm{C} \\
(\mathrm{g} / \mathrm{mL})\end{array}$ & $\begin{array}{c}\text { Heat of } \\
\text { combustion }^{\text {b }} \\
\text { (M)/kg) }\end{array}$ & $\begin{array}{c}\text { Water } \\
\text { content }^{\mathrm{c}} \\
\text { (\%vol.) }\end{array}$ & $\begin{array}{l}\mathrm{A} / \mathrm{F}_{\text {st }} \\
\text { ratio }^{\mathrm{d}}\end{array}$ \\
\hline Diesel & 100.0 & - & - & - & - & - & 4.1 & 0.83 & 45.8 & 0.01 & 14.86 \\
\hline Palm oil-Diesel (PD) & 50.0 & 50.0 & - & - & - & - & 11.7 & 0.88 & 42.5 & 0.06 & 13.49 \\
\hline Biodiesel-Diesel (BD) & 50.0 & - & - & - & - & 50.0 & 4.5 & 0.87 & 39.2 & 0.09 & 13.50 \\
\hline \multicolumn{12}{|l|}{ Microemulsion fuel } \\
\hline 1-butanol (MO+But) & 32.5 & 32.5 & 6.0 & 9.0 & 20.0 & - & $4.3^{\mathrm{a}}$ & 0.85 & 39.2 & 0.16 & 12.39 \\
\hline 1-octanol (MO+Oct) & 29.0 & 29.0 & 6.0 & 16.0 & 20.0 & - & $4.3^{\mathrm{a}}$ & 0.87 & 39.2 & 0.16 & 12.47 \\
\hline 1-decanol (MO+Dec) & 27.5 & 27.5 & 6.0 & 19.0 & 20.0 & - & $4.6^{\mathrm{a}}$ & 0.88 & 39.5 & 0.18 & 12.50 \\
\hline
\end{tabular}

${ }^{\text {a }}$ Data from our previous work [18]

${ }^{\mathrm{b}}$ Heat of combustion of fuels were measured using bomb calorimeter (ASTM D240).

${ }^{\mathrm{c}}$ Water content was measured using Karl Fischer (KF) titrator (ASTM D6304).

${ }^{\mathrm{d}}$ Air-fuel ratio is the mass ratio of air to fuel present in an internal combustion engine during stoichiometric mixture.

(36.8-39.6 cSt at $\left.40^{\circ} \mathrm{C}\right)$. It was, however, still more than double the kinematic viscosity of the No. 2 diesel standard. The higher viscosity of the neat palm oil, as compared to the diesel's, is attributable to the complex mixture of the palm oil, which typically has a high molecular weight and large molecular structure.

As consider the kinematic viscosity of the microemulsion fuels; our previous work [22], the microemulsion fuels (mixtures of the diesel/palm oil, ethanol, surfactant and cosurfactant) were observed to have kinematic viscosity results at $40^{\circ} \mathrm{C}$, for all the test fuels, that were relatively close to that of a regular diesel (ranging from 4.3 to $4.6 \mathrm{cSt}$ ) (See Table 1).

A similar blending technique can be applied for a neat biodiesel and regular diesel mixture as the biodiesel/diesel blends had a competitive net fuel viscosity result. However, the costs of biodiesel production as well as the environmental burdens from their byproducts, wastewater and spent chemicals still pose challenges to widespread implementation.

The heat of combustion is frequently a parameter used to evaluate the fuel consumption of diesel engines. The results show that all the microemulsion biofuels had lower combustion energy than the diesel and PD but the same as the BD. As a result, the lower heating content of the microemulsion biofuels can be said to affect their fuel economy because they induced a greater fuel requirement for the engine to generate the same amount of electrical power. The relation of the heating value and fuel consumption is consistent with the fuel consumption results for the diesel test engine reported below.

The determination of water in composite microemulsionbased fuel has been carried out by volumetric Karl Fischer (KF) titration. For this study, the result shows that the water content in microemulsion fuels was $0.16-0.18 \%$ which is higher than that in commercial diesel fuel (0.01\%) and palm oil-diesel blends $(0.06 \%)$ as shown in Table 1 . Thus, it is implied that the water content in the microemulsion fuel mainly come from the anhydrous ethanol (99.5\% purity) in its composition.

Regarding the effects of the cosurfactants, as the number of the carbon chain length, C4 to C10, in the cosurfactant increased, a small increase occurred in the overall hydrophobicity of the surfactant system to stabilize the oil and ethanol phases. However, both the water content and the heat of combustion of the microemulsion biofuels were not significantly affected by increases in the number of the carbon chain length in the cosurfactant molecule.

\subsection{Fuel Consumption}

The fuel consumption $(\mathrm{g} / \mathrm{h})$ at two engine loads for the diesel, microemulsion fuels, palm oil-diesel blends, and biodiesel-diesel blends is summarized in Fig. 2. All sets of fuel performance tests demonstrated that the fuel consumption was much greater at $1,000 \mathrm{~W}$ than $500 \mathrm{~W}$, as expected. The fuel consumption of the microemulsion biofuels ranged from $364-377 \mathrm{~g} / \mathrm{h}$ at $500 \mathrm{~W}$ and $502-530 \mathrm{~g} / \mathrm{h}$ at $1,000 \mathrm{~W}$, which ranged from 23 to 27 percent and 7 to 13 percent more than the fuel requirement for the diesel

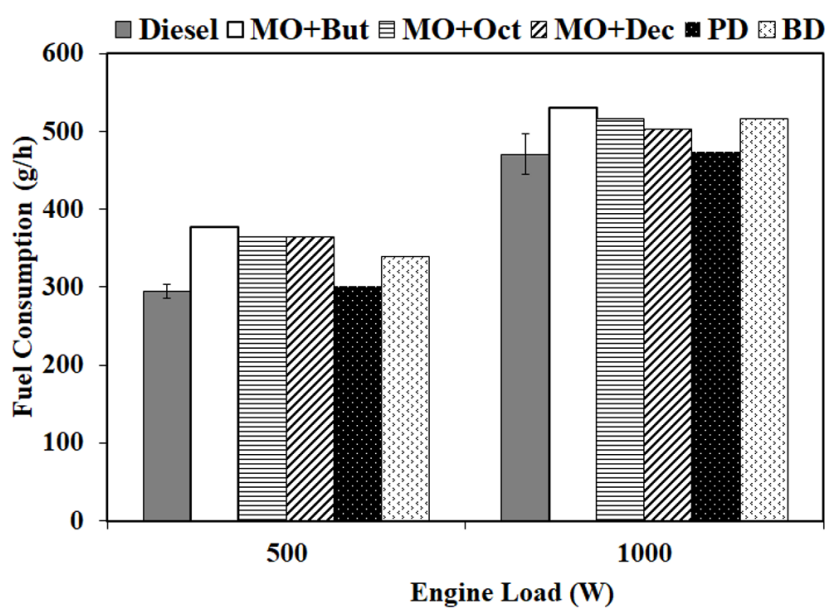

Fig. 2. Fuel consumptions of diesel, microemulsion fuels, palm oil-diesel blends, and biodiesel-diesel blends (see Table 1 for abbreviations). 


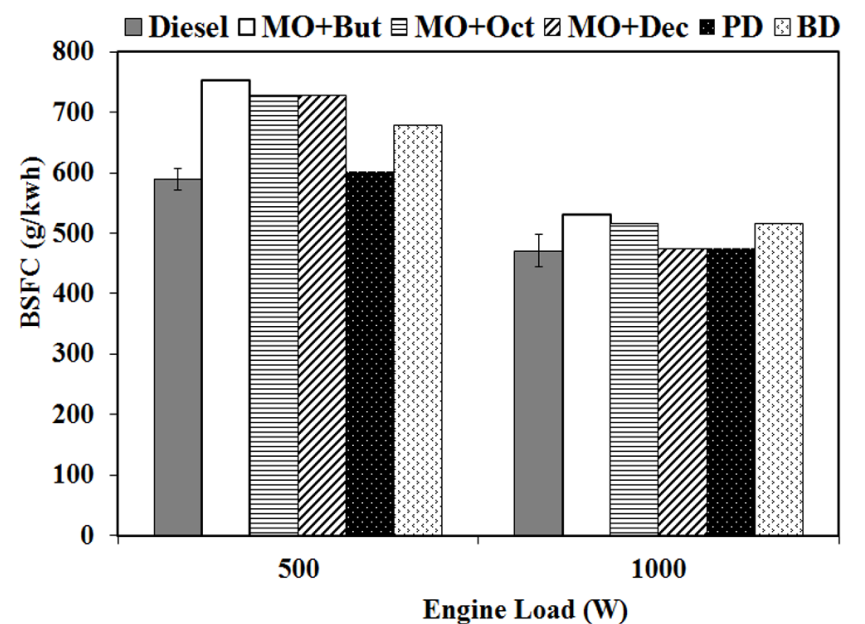

Fig. 3. Break specific consumption for diesel, microemulsion fuels, PD, and $\mathrm{BD}$.

fuel at $500 \mathrm{~W}(295 \mathrm{~g} / \mathrm{h})$ and the diesel fuel at 1,000 W (471 g/h), respectively. This is because the alkanols (i.e., ethanol and cosurfactants) have a lower calorific value (see Table 1) than that of the diesel fuel; therefore, the net energy values of the microemulsion biofuels were significantly reduced when large volumes of the alkanols were present in the systems [28].

The PD is a mixture of palm oil and diesel at a volumetric ratio of 1:1. At both engine-load conditions, the PD produced a slightly higher fuel consumption (only 1-2\%) to that of diesel. From these results, it is concluded that the fuel consumption under these conditions was not affected by the fraction of the palm oil and diesel blend due to its heat of combustion (see Table 1).

Fig. 3 shows the BSFC results of all the fuels. The BSFC indicates the amount of fuel consumption that was needed to generate the same energy power. The BSFC of all the fuels decreased as engine loads increased due to the higher fuel combustion and lower heat losses. Moreover, it is interesting to note that the BSFC of all the microemulsion biofuels increased for all the engine loads. The BSFC increments tended to become smaller as the engine load increased. The engine consumed more microemulsion biofuels than the neat diesel fuel in order to generate the same engine output because of the lower heat content of alcohol in the fuel blends.

\subsection{Exhaust Emissions}

\subsection{1. $\mathrm{NO}_{\mathrm{x}}$ emissions}

The $\mathrm{NO}_{\mathrm{x}}$ emissions were measured in the exhaust for the different microemulsion biofuels as shown in Fig. 4. In general, the sources of $\mathrm{NO}_{\mathrm{x}}$ in the combustion process are mainly generated from thermal $\mathrm{NO}_{\mathrm{x}}$ and fuel $\mathrm{NO}_{\mathrm{x}}$. The combustion (flame) temperature, the residence time of nitrogen at that temperature, and oxygen content in an engine cylinder are the major factors affecting the formation of $\mathrm{NO}_{\mathrm{x}}[28,29]$. In general, more fuel is consumed and combusted in the cylinder when engine loads increase, which results in higher gas temperatures and $\mathrm{NO}_{\mathrm{x}}$ emissions. A contrary trend was observed in Fig. 4, where $\mathrm{NO}_{\mathrm{x}}$ emissions decreased as the engine load increased for all microemulsion biofuels.

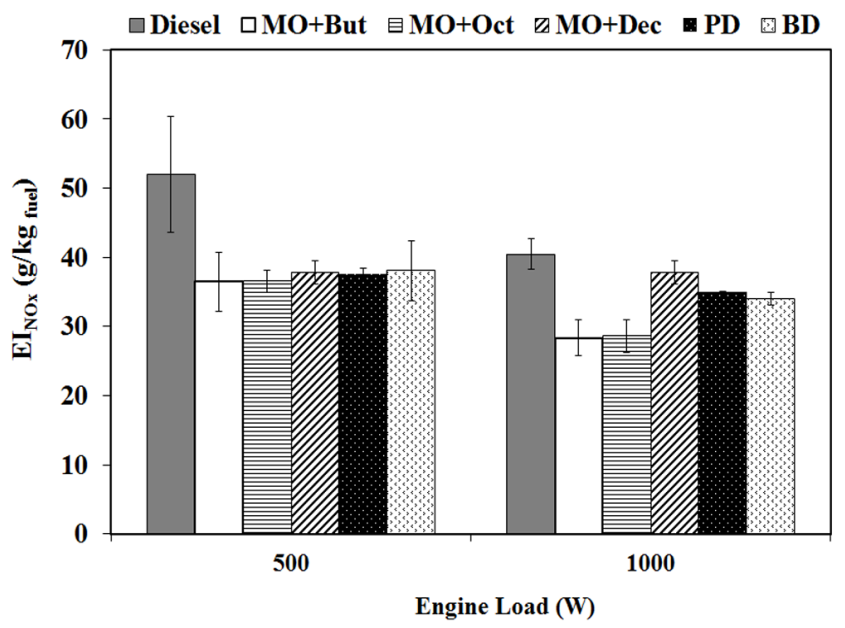

Fig. 4. $\mathrm{NO}_{\mathrm{x}}$ emissions for diesel, microemulsion fuels, $\mathrm{PD}$, and $\mathrm{BD}$.

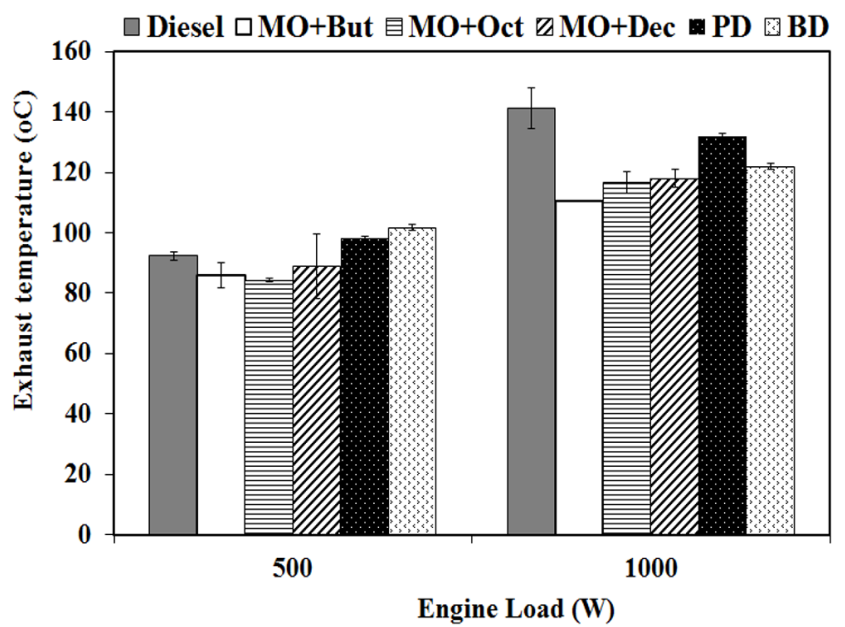

Fig. 5. The exhaust gas temperature of diesel, microemulsion fuels, $\mathrm{PD}$, and $\mathrm{BD}$.

A comparison among the fuels point to $\mathrm{NO}_{\mathrm{x}}$ emissions from all microemulsion fuels as being lower than those of the neat diesel (Fig. 4.), PD, and BD fuels at both engine loads, with the statistical difference being more apparent for the higher load $(1,000 \mathrm{~W})$. This reduction of $\mathrm{NO}_{\mathrm{x}}$ could be due to the evaporation of alcohol (i.e., the ethanol cosurfactant) dispersed in the microemulsified fuels, leading to lower gas temperatures in the cylinder as a result of their higher latent heat of vaporization. Moreover, the limitation of air supply in term of oxygen and nitrogen available to form $\mathrm{NO}_{x}$ in a stoichiometric mixture (Table 1) [30]. Thus, $\mathrm{NO}_{\mathrm{x}}$ emissions from microemulsion fuels were reduced by replacing a portion of the diesel with ethanol and the cosurfactant.

Fig. 5 presents dissimilar exhaust gas temperatures for all the tested fuels versus those of the two engine loads. It was observed that all of the microemulsion fuels emitted lower exhaust gas temperatures than the other fuels because of the lower heating value of ethanol and the cosurfactants in the microemulsion fuels. Accordingly, the lower exhaust gas temperature 
can explain the lower $\mathrm{NO}_{\mathrm{x}}$ emissions of the microemulsion fuels. A comparison among the types of cosurfactants in the microemulsion fuels showed that the $\mathrm{NO}_{\mathrm{x}}$ emissions were not affected by varying the carbon chain lengths in the fuels' cosurfactants $(p>0.05)$. This is because the heating values (see Table 1) and exhaust gas temperatures of the microemulsion biofuels were not meaningfully different.

\subsection{2. $\mathrm{CO}_{2}$ emissions}

The $\mathrm{CO}_{2}$ emissions of the different fuels from two engine loads are shown in Fig. 6. Increasing the engine loads increased the $\mathrm{CO}_{2}$ emissions for all the microemulsion biofuels. The microemulsion biofuels produced lower $\mathrm{CO}_{2}$ emissions than did the neat diesel, PD, and BD fuels, with the effect being more apparent at the higher load. Among three microemulsified fuels, no significant difference in the $\mathrm{CO}_{2}$ emissions was observed. The reduction of $\mathrm{CO}_{2}$ in the microemulsion fuels could have been due to the oxygen content in the biofuel, which is a dominant component found in palm oil and ethanol and methyl oleate. The carbon composition was comparatively lower at the same amount of fuel consumed; therefore, the $\mathrm{CO}_{2}$ discharged from the microemulsion biofuels was lower. As opposed to diesel, at the partial load, the PD and $\mathrm{BD}$ had higher $\mathrm{CO}_{2}$ emissions, whereas at the full load the results were opposite.

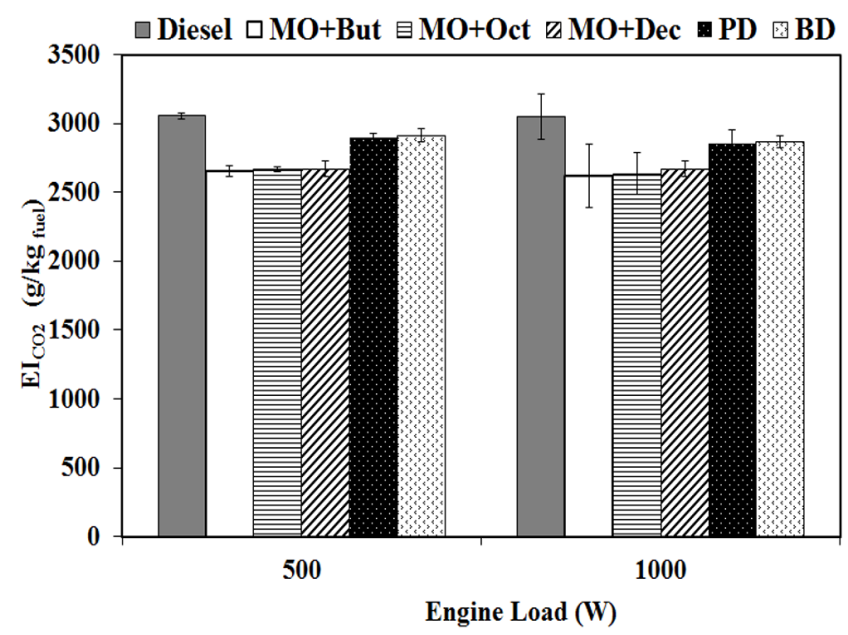

Fig. 6. $\mathrm{CO}_{2}$ emissions for diesel, microemulsion fuels, $\mathrm{PD}$, and $\mathrm{BD}$.

\subsection{3. $\mathrm{CO}$ emissions}

Fig. 7 shows the CO emissions from the different fuels: the diesel, microemulsion fuels, palm oil-diesel blends, and biodiesel-diesel blends. The CO emissions from the microemulsion biofuels at two-load conditions were slightly higher than the neat diesel's. The increase in CO emissions may have possibly been due to the higher viscosity and lower $\mathrm{A} / \mathrm{F}_{\text {st }}$ ratio, resulting in the incomplete combustion of the mixed oil/ethanol- $\mathrm{O}_{2}[3$, 31]. However, the data showed that the CO emissions from the microemulsion biofuels were not significantly different from the neat diesel's $(p>0.05)$.

The CO emissions among the microemulsion biofuels (i.e., butanol-fuel, octanol-fuel, and decanol-fuel blends) were not

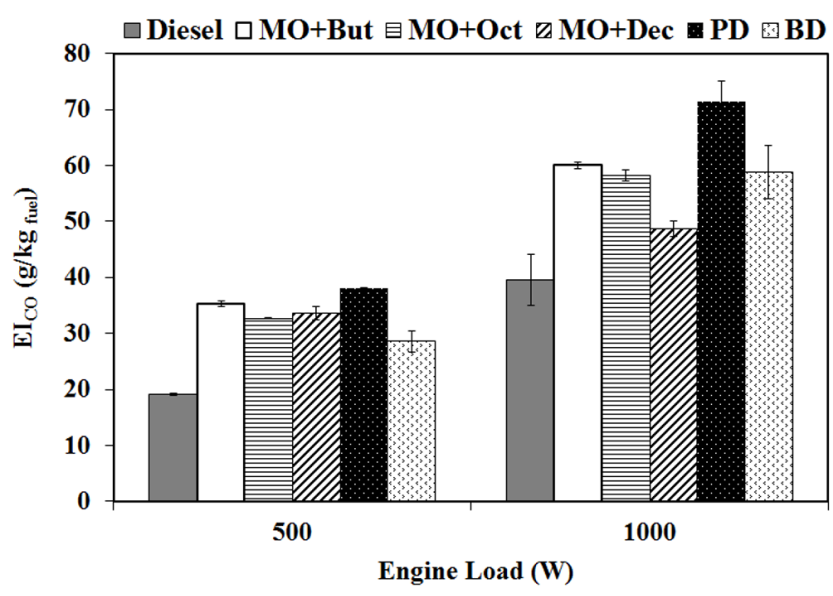

Fig. 7. CO emissions for diesel, microemulsion fuels, PD, and BD.

significantly different either. However, the CO emissions for the butanol-microemulsion biofuels tend to be higher than those of the other microemulsion fuels. The PD produced the highest CO emissions. This is because the high viscosity of the PD (see the viscosity values in Table 1) can cause poor fuel-spray characteristics in the ignition, thus leading to CO formation from incomplete combustion [18, 28]. This points to the benefit of using alcohol-based additives, which lower the viscosity and thus the CO emissions.

\section{Conclusions}

The performance of palm oil based-microemulsion fuels was evaluated by virtue of fuel economy and the quality of their exhaust gas emissions were examined through a small-sized DI diesel engine at an engine speed of 1,200 rpm and two different engine loads. The fuel performances of the microemulsion based biofuels versus diesel resulted in the following observations:

1) Palm oil based microemulsion fuels show promise as a biofuel for single-cylinder diesel engines without having to perform any engine modifications. Specifically, the kinematic viscosity and other fuel performance indicators were shown to be comparable with those of the No. 2 diesel.

2) The microemulsion fuels studied had slightly higher fuel consumption compared to the regular diesel fuel under all engine operating conditions because of their lower heat of combustion.

3) The microemulsion fuels showed significantly lower $\mathrm{NO}_{\mathrm{x}}$ and $\mathrm{CO}_{2}$ emissions and exhaust gas temperatures compared with the diesel fuel. Meanwhile, the CO emissions under all engine loads were significantly higher than the CO emissions of the diesel fuel.

With regard to the effects of the cosurfactants on the microemulsion biofuels, the $\mathrm{NO}_{\mathrm{x}}$ and $\mathrm{CO}$ emissions as well as the exhaust gas temperatures under all load conditions were not significantly different. Nevertheless, the octanol-microemulsion biofuel tended to have lower $\mathrm{CO}$ and $\mathrm{NO}_{\mathrm{x}}$ emissions than the butanol- and decanol-microemulsion fuels as a result of the increment of the $\mathrm{O}_{2}$-fuel mixture. When compared with the other 
alternative fuels (PD and BD), the microemulsion biofuels exhibited significantly lower the exhaust gas temperatures and the $\mathrm{NO}_{\mathrm{x}}$, and $\mathrm{CO}_{2}$ emissions. These results indicate that microemulsion fuels can be used as environmentally friendly alternatives in light-duty diesel engines, such as single-cylinder engines, which are most widely used in agricultural applications.

\section{Acknowledgments}

Financial support was provided by the new researcher grant from the Thailand Research Fund (MRG 6080015). Finally, the authors would like to thank Miss Ramnaree Netvichien, the research assistant at Chulalongkorn University.

\section{References}

1. Dunn RO, Bagby MO. Low-temperature phase behavior of vegetable oil/co-solvent blends as alternative diesel fuel. $J$. Am. Chem. Soc. 2000;77:1315-1323.

2. Lif A, Holmberg K. Water-in-diesel emulsions and related systems. Adv. Colloid Interface Sci. 2006;123-126:231-239.

3. Nguyen T, Abraham J, Ramallo M, Wagner D, McLennan J. Formulation of canola-diesel microemulsion fuels and their selective diesel engine performance. J. Am. Chem. Soc. 2012;89:1905-1912.

4. Nanaki EA, Koroneos CJ. Comparative LCA of the use of biodiesel, diesel and gasoline for transportation. J. Clean. Prod. 2012;20:14-19.

5. López JM, Gómez Á, Aparicio F, Javier Sánchez F. Comparison of GHG emissions from diesel, biodiesel and natural gas refuse trucks of the City of Madrid. Appl. Energ. 2009;86:610-615.

6. Arpornpong N, Sabatini DA, Khaodhiar S, Charoensaeng A. Life cycle assessment of palm oil microemulsion-based biofuel. Int. J. Life Cycle Assess. 2015;20:913-926.

7. Altın R, Çetinkaya S, Yücesu HS. The potential of using vegetable oil fuels as fuel for diesel engines. Energ. Convers. Manage. 2001;42:529-538.

8. Ali Y, Hanna MA. Alternative diesel fuels from vegetable oils. Bioresour. Technol. 1994;50:153-163.

9. Balat M. Modeling vegetable oil viscosity. Energ. Source. Part A. 2008;30:1856-1869.

10. Abollé A, Kouakou L, Planche H. The viscosity of diesel oil and mixtures with straight vegetable oils: Palm, cabbage palm, cotton, groundnut, copra and sunflower. Biomass Bioenerg. 2009;33:1116-1121.

11. Knothe G, Steidley KR. Kinematic viscosity of biodiesel fuel components and related compounds. Influence of compound structure and comparison to petrodiesel fuel components. Fuel 2005;84:1059-1065.

12. Agarwal AK, Rajamanoharan K. Experimental investigations of performance and emissions of Karanja oil and its blends in a single cylinder agricultural diesel engine. Appl. Energ. 2009;86:106-112.

13. Machacon HTC, Shiga S, Karasawa T, Nakamura $H$. Performance and emission characteristics of a diesel engine fueled with coconut oil--diesel fuel blend. Biomass Bioenerg. 2001;20:63-69.

14. Galan M-I, Bonet J, Sire R, Reneaume J-M, Pleşu AE. From residual to useful oil: Revalorization of glycerine from the biodiesel synthesis. Bioresour. Technol. 2009;100:3775-3778.

15. Lee Y, Shafaghat H, Kim J-k, et al. Upgrading of pyrolysis bio-oil using $\mathrm{WO}_{3} / \mathrm{ZrO}_{2}$ and Amberlyst catalysts: Evaluation of acid number and viscosity. Korean J. Chem. Eng. 2017;34:2180-2187.

16. Pagliaro M, Ciriminna R, Kimura H, Rossi M, Della Pina C. From glycerol to value-added products. Angew. Chem. Int. Ed. 2007;46:4434-4440.

17. Shi $\mathrm{X}, \mathrm{Yu} \mathrm{Y}, \mathrm{He} \mathrm{H}$, et al. Emission characteristics using methyl soyate-ethanol-diesel fuel blends on a diesel engine. Fuel 2005;84:1543-1549.

18. Hazar H, Aydin H. Performance and emission evaluation of a CI engine fueled with preheated raw rapeseed oil (RRO)diesel blends. Appl. Energ. 2010;87:786-790.

19. Qi DH, Yang K, Zhang D, et al. Experimental investigation of a turbocharged CRDI diesel engine fueled with Tung oil-diesel-ethanol microemulsion fuel. Renew. Energ. 2017;113:1201-1207.

20. Yue H, Liu Z. Densities and surface tensions of binary mixtures of biodiesel, diesel, and n-butanol. Korean J. Chem. Eng. 2016;33:1692-1697.

21. Devarajan Y, Nagappan BK, Munuswamy DB. Performance and emissions analysis on diesel engine fuelled with cashew nut shell biodiesel and pentanol blends. Korean J. Chem. Eng. 2017;34:1021-1026.

22. Arpornpong N, Attaphong C, Charoensaeng A, Sabatini DA, Khaodhiar S. Ethanol-in-palm oil/diesel microemulsionbased biofuel: Phase behavior, viscosity, and droplet size. Fuel 2014;132:101-106.

23. Attaphong C, Sabatini DA. Phase behaviors of vegetable oil-based microemulsion fuels: the effects of temperatures, surfactants, oils, and water in ethanol. Energ. Fuel. 2013;27 6773-6780.

24. Attaphong C, Singh V, Balakrishnan A, et al. Phase behaviors, fuel properties, and combustion characteristics of alcohol-vegetable oil-diesel microemulsion fuels. Int. J. Green Energy 2016;13:930-943.

25. Love ND, Parthasarathy RN, Gollahalli SR. Effect of iodine number on $\mathrm{NO}_{\mathrm{x}}$ formation in laminar flames of oxygenated biofuels. Int. J. Green Energy 2009;6:323-332.

26. Attaphong C, Do L, Sabatini DA. Vegetable oil-based microemulsions using carboxylate-based extended surfactants and their potential as an alternative renewable biofuel. Fuel 2012;94:606-613.

27. Singh PJ, Khurma J, Singh A. Preparation, characterisation, engine performance and emission characteristics of coconut oil based hybrid fuels. Renew. Energ. 2010;35:2065-2070.

28. Wang YD, Al-Shemmeri T, Eames P, et al. An experimental investigation of the performance and gaseous exhaust emissions of a diesel engine using blends of a vegetable oil. Appl. Therm. Eng. 2006;26:1684-1691.

29. Doğan O. The influence of n-butanol/diesel fuel blends utilization on a small diesel engine performance and emissions. 
Fuel 2011;90:2467-2472.

30. Qi DH, Bae C, Feng YM, Jia CC, Bian YZ. Combustion and emission characteristics of a direct injection compression ignition engine using rapeseed oil based micro-emulsions. Fuel 2013;107:570-577.
31. Xing-cai L, Jian-guang Y, Wu-gao Z, Zhen H. Effect of cetane number improver on heat release rate and emissions of high speed diesel engine fueled with ethanol-diesel blend fuel. Fuel 2004;83:2013-2020. 